\title{
ESP Administration and ESP Teacher Training
}

\author{
John Swales and Hugh L'Estrange
}

\begin{abstract}
A good knowledge of course design, methodology and materials production will not turn an ESP teacher into a future administrator. Since many students on master's courses will probably look for posts with administrative responsibility, the Diploma/MSc course in Teaching English for Specific Purposes at the University of Aston in Birmingham has offered a special optional course called "ESP Administration". This paper discusses the case study approach used in the course. The details of the case are in two parts: Background Papers, describing the (imaginary) country and Polytechnic ESP Unit; and Action Papers, being three letters from outside bodies requesting the unit to provide new courses. The scarcity of published articles (a review is included) was one factor which encouraged the casestudy approach. Another reason for using a case study is that it demands responses at many different levels.

The option has been tried out as both an extensive and an intensive course. Reactions have been extremely diverse, but all groups have tended to concentrate more on course design, timetabling, or the "unionization position" than on other aspects of administration such as good customer relations. The case study can develop in many directions but the character of each realisation depends on the interaction between the participants. One of the unresolved questions is how and at what point to offer explicit teaching on administrative problems to consolidate the undoubted learning that takes place through the case-study experience.
\end{abstract}

In an extensive ESP teacher-training programme such as the Diploma/ MSc in Teaching English for Specific Purposes at the University of Aston, few people would be surprised to find that Course and Syllabus Design is a major component; in fact, it is one of the five major courses, the others being: Linguistic Features of ESP-Relevant Varieties of English, Approaches to Text and Discourse Analysis, Methodology, and Materials Production. Although there may be considerable controversy regarding the correct principles of course and syllabus design, there is much less disagreement about both the importance of course design considerations in ESP enterprises and about the need to establish some sort of principled basis from which to proceed. Thus there has emerged in recent years a sizeable course design literature, and several of the leading figures in ESP, such as Candlin, Mackay, and Widdowson, have written extensively on this subject (see, for example, Candlin and Breen 1979, Mackay 1981a, and Widdowson 1981). Equally indicative of the key role ascribed to course design are events such as the British Council devoting two of its annual conferences for its own specialised staff to this topic, as it did at Dunford House in 1978 and 1979 (British Council n.d.). 
However, there is something of a paradox here. The more seriously course design is discussed and analysed as an activity properly reflecting sociolinguistic enquiry, the investigation of educational need, and psycholinguistic theory, the less certainly can the schemes for course design implementation be applied in the realities of particular language learning situations. As the inventories of relevant course design factors become more elaborate, so course design is in danger of becoming an educational exercise in its own right, rather than being seen as a set of utilisable skills in the service of an ESP programme-and this tendency toward intellectualisation is likely to be particularly strong on postgraduate courses offered to an international group of students. Therefore, we decided that we would need to offer an opportunity to offset the elegance of course design theory with the brutalities of ESP administration-and it is with our attempts to "teach" ESP administration that the remainder of this paper is concerned. The paper is co-authored: Swales sets the scene and evaluates the reactions and performance of the participants from the viewpoint of originator of the ESP administration materials; L'Estrange discusses the events and outcomes from the viewpoints of, initially, a participant and, subsequently, a tutor.

In contrast to course design, there appears to be very little written on ESP administration, the only articles known to us dealing directly with this topic being the two by Erik Christy in the English for Science and Technology newsletter in 1978. However, within the course design literature, there is a minority of papers dealing usefully with some of the realities of course design planning. There are the illuminating and splendidly honest retrospective accounts of courses by Drobnic and by HirayamaGrant and Sedgwick in the English for Specific Purposes: Science and Technology volume (1978). We can also find in the various issues of the British Council's ELT Documents series a small number of papers that stress the importance of sensible and sensitive "on the ground" administrative decision making, such as Abbott (1978), Chamberlain and Flanagan (1978), and Swales (1980). In Languages for Specific Purposes (1981), edited by Mackay and Palmer, the papers by Mackay and Bosquet and by Bachman and Strick offer a wider and more pragmatic perspective on course design than is usually found. Mackay (1981b), in an important paper entitled "Accountability in ESP Programs", argues convincingly for a comparable analytic rigor and sense of educational responsibility in course evaluation as is customarily only applied to course design, in order to ensure that the level of cost effectiveness of ESP programmes can be properly scrutinised by the sponsors. Finally, Sinclair (1978), in an impressive overview drawn partly from his own considerable experience, discusses a wide range of problems that can arise in ESP project work and offers various kinds of solution, commenting inter alia, "Many, perhaps most, ESP projects are actually carrying unappreciated responsibilities, and may be regarded finally as flawed for reasons which are lightly connected to English teaching." (Sinclair 1978: 107) Discussion of quotations such as this can open up the wider perspectives on course design that an ESP administration course hopes to provide. 
On the other hand, the relative paucity of papers on matters pertaining to ESP administration has at least the advantage of persuading the teacher trainer that there is no sufficient or accessible body of received knowledge within the ESP profession to justify mounting a formal, taught course in ESP Administration, thus leaving the two main options of either providing a lecture course with major subventions from those who teach Management or Business Administration, or of adopting a case study approach. We at Aston have experimented with the latter option, and with perhaps enough initial success to warrant this preliminary report.

Although to our knowledge the case study approach has not previously been used in this way, the following case does reflect contemporary Management teaching practice (Candlin, Charles and Willis 1982) in that it has been so designed that there are no "right solutions" to the problems presented. The aims of the case were to force each four-member team to react to simulated realities in a variety of ways.

A. To respond to requests for courses by:

(i) establishing good communications with the potential customers so that as much information as possible can be obtained, good rapport established, and hazards in precourse administration minimised;

(ii) preparing a range of costings according to various sets of criteria;

(iii) considering the redeployment of existing staff and, where necessary, engaging in the process of selecting additional staff;

(iv) drawing up outline course proposals that would be comprehensible and acceptable to all parties.

B. To respond to the changed potential of the ESP Unit (which each team comprised) by prioritising the following benefits, which would arise from the expanded work of the Unit:

(i) a share of the enhanced income for the Unit itself;

(ii) the opportunity to undertake more "interesting" ESP teaching;

(iii) the increased reputation of their ESP Unit resulting from taking on new activities;

(iv) individual professional development and career prospects.

The case study documents now follow. We have given them almost in their entirety, partly because it would be difficult to evaluate the programme without them, and partly because others might wish to adapt the documents for their own ESP teacher-training purposes. The documents are of two kinds: Part A-Background Papers, and Part B-Action Papers.

\section{THE CASE STUDY}

\section{Part A-Background Papers}

Possible Developments in the English Unit at Hornby Polytechnic, Tefloonia

\section{The State of Tefloonia}

Tefloonia is a small ex-British colony with a population of about five million, situated between the Tropic of Cancer and the Tropic of Capricorn. Although 
Tefloonia is a developing country, it is relatively well advantaged; there is a large and internationally successful mining industry, it has some of the finest timber forests in the world, and especially in the last few years it has suffered something of a boom in tourism, especially from the educated middle classes of the Northern Hemisphere. The government of Tefloonia is a benevolent dictatorship, and it is the benevolence of its self-appointed president that has allowed a relatively relaxed way of life to develop, and which in turn has underpinned the emerging tourist industry. The capital of Tefloonia is Hornby, a graceful city situated at the centre of the country, and in which life is a little slow, but relatively agreeable. As one visiting journalist described it, Hornby is highly civilised but little cultured.

\section{The Language Situation in Tefloonia}

Although Tefloonia is an ex-British colony, English was never fully established as a second language, and today some 15 years after independence, it is only spoken naturally by Tefloonian citizens of the middle and professional classes. The national language of the country is Tefloon, and this is widely distributed, although in certain areas, such as in the forest regions, there are a number of small minority languages. Tefloon itself belongs to the Efloon group of languages that are spoken in Tefloonia and in a number of neighbouring countries. These languages are all written in a roman script. They are only mutually intelligible with difficulty, and as a result a creolised version of Tefloon has developed for purposes of trade and international communication. Tefloon itself is, however, not a major language, and is not useful outside the corner of the continent of which Tefloonia is a part. In Tefloonia then, we find an "advanced EFL situation"; for instance, there are three daily newspapers in Hornby, one of which is in English; for example, there is a fifteen-minute world news summary in English on Tefloonian radio each evening; for example, many members of Tefloonian society, especially the younger members, are accustomed to going to the cinema and seeing films produced through the medium of English, either with or without Tefloon subtitles.

\section{The Educational System}

English is taught for eight years in school, and the secondary school leaving standard in English compares relatively favourably with that obtained in many other parts of the world. The government places considerable emphasis on a useable command of English for its own middle-rank employees, and the private sector does likewise; therefore, there are considerable motivations for students and parents to concentrate on this subject. In addition, Tefloonia has benefited from an excellent upcountry teachertraining college, which has a particularly high reputation for producing cadres of junior secondary English teachers greatly skilled in imparting the content of the secondary school English course to their pupils. The average Tefloonian secondary school leaver, therefore, probably has an English equivalent rather higher than a British ' $O$ '-level in French.

Apart from the teacher-training sector, there are only two institutes of higher education in the country. The premier institution is the University of Tefloonia. This is an ex-colonial institution, which maintains an ivorytower orientation to the rest of the community and runs a series of traditional degree courses that have changed comparatively little in the decade-anda-half since independence. The University is perhaps more concerned about maintaining its status and preserving what it considers to be an appropriate level of academic freedom independent of government interference than it is about its role in the development of Tefloonia. As far as English is concerned, there is a degree in English Language and Literature and a degree in English Language and Linguistics. The senior members of the English 
Department are all literature specialists and do not consider that the less than fully satisfactory level of English language standard of their students on entry should in any way inhibit them from embarking upon Chaucer and Shakespeare in the first year. There are, however, one or two younger members of the Department of perhaps a more realistic cast of mind who have in the last year or two begun to take interest in such matters as error analysis and the teaching of essay writing. By and large the staff of the English Department are relatively underworked. On the Linguistics side, the course falls into two distinct parts: on the one hand, there are standard courses in theoretical linguistics and transformational grammar, etc.; on the other, the Head of the Department runs courses in field linguistics. This relates to the Head of Department's position as director of a Ford Foundation sponsored language survey of Tefloonia, and he himself spends much of his time in the forest area tracing minority language boundaries and usages.

The other higher education institute is Hornby Polytechnic. Hornby Polytechnic was established with United Nations aid about ten years ago, and has a radically different orientation to that of the University. Its courses are deliberately designed to reflect both the public and private sectors' manpower needs and it has thus evolved a series of Advanced Diploma programmes that relate to Engineering, Administration, Forestry, Preventive Medicine, Transportation, Tourism, and so on. However, both the University and the Polytechnic have the same approach to the problem of medium of instruction. In both cases, the medium of instruction for all reading and written work is decreed as being English; as far as the spoken side is concerned, whether it be lectures or more informal tutorials, the medium of instruction is taken to be either Tefloon or English, as previously announced by the member of staff responsible for a particular course.

\section{The English Unit}

The English Unit at Hornby Polytechnic has an establishment of four lecturers. As the Unit is small, there is no official Head, but one lecturer acts informally as Lecturer-in-Charge. The agreed workload for lecturers is a maximum of 15 hours per week. The workload of the Lecturer-inCharge is reduced by three hours to compensate for administrative duties.

All members of the Polytechnic are supposed to spend 20 percent of their time on research, and in fact, promotion in the Polytechnic depends equally on:

(a) teaching effectiveness (monitored by a staff-student committee);

(b) research (monitored by a staff committee);

(c) administrative efficiency (monitored by an academic and administrative committee).

Academic Year. The Academic Year runs over two 16-week semesters, the first from early September to the end of December. There is then a three-week holiday. The second semester begins in the last week of January and ends in the third week of May. Exams take place in June.

First Year Programme. Five hours per week for English, divided into seven groups according to the seven Advanced Diploma courses (the size of the groups given in brackets).

(1) Transportation and Highway Engineering

(2) Forestry Production

(3) Commerce and Banking

(5) Mining Technology

(6) Medical Technology

(7) Management for Tourism 
Second Year Programme. At the end of the first year, students reaching a $B$ average are exempted from further English. The remaining students then have two hours per week. The average class size is usually reduced by about half, largely as a result of exemption, but also because about five percent of the students fail their first year.

Further Information. This programme is relatively well established, and basically adequate materials exist in all seven areas. Although revisions are continually being made, there are no plans for total reform, despite anxieties as to whether the structural-functional courses (influenced in particular by the Nucleus series) are "up to date."

The English Unit also has a small reference textbook library, a number of ESP articles, its own duplicator, two overhead projectors and several audio cassette recorders.

At the present time there are no parttimers in the Unit, but there have been in the past. Indeed the Unit is often approached about parttime work; one or two of the younger lecturers at the University have expressed a willingness to take part in what they consider to be the Unit's "pedagogically interesting" activities.

The Unit is responsible to the Assistant Dean for Internal and External Services (ADIES).

Private Work, Consultancy, Surplus Income. Occasionally members of staff give private lessons, or act as examiners. The English Unit has never officially been involved in a consultancy, nor has it ever run any "incomegenerating" courses before. The English Unit does not know what would happen to any money earned, but presumably, the Assistant Dean has some ideas.

\section{ESP Administration-Costs and Prices}

Hornby Polytechnic Salary Scale (in TEFL: 1 TEFL $=£ 0.25=\mathrm{US} \$ 0.50$ ). Lecturer: $16,000-32,000$ p.a. $(+1000$ per year $)$ Secretary: $6,000-10,000$ p.a. $(+400$ per year $)$

Parttime Teaching Rates.

Lecturer:

Assistant Lecturer:

16 TEFL per hour 12 TEFL per hour

Equipment, Books, Reprographics, etc.

As per suppliers' list prices, converted into TEFL equivalents.

\section{Part B-Action Papers}

The case study opens with the Assistant Dean asking his ESP Unit to meet him in order to discuss their possible responses to the three recently received letters. The Assistant Dean can legitimately (?) claim that the ESP Unit is not currently working at maximum capacity ( 57 hours per week), its actual teaching load being only 49 hours a week, and can therefore suggest that the University Administration is "owed something" by the ESP Unit. Being an enterprising man, and one concerned to keep the Polytechnic closely involved in his country's national development, he can also argue that each of the requests has considerable merit, although the sort of benefits that might accrue varies very considerably-financial, political, educational, institutional prestige, ESP research development, and so on. The Assistant Dean is therefore looking for a positive response. 


\section{Letter from Piflonian Embassy re W.H.O. Medics}

The Embassy of Piflonia

President Avenue

Hornby

(Te1: 281)

John Swales Esq.

Education Attaché's Office

Assistant Dean

Hornby Polytechnic

(1ast week)

our ref: HP/WHO/101/102/103

your ref: $E S / M B / 661 / 662 / 663$

W.H.O. Scholars in Advanced Medical Technology

Dear Mr. Swales,

Following the signing of the agreement last month between our Ambassador, your Principal and the W.H.O. representatives in Piflonia and Tefloonia, $I$ have been instructed to liaise with you à propos the scheme whereby 20 Piflonian Medical technicians will follow your 3-year Diploma in Medical Technology. I am happy to confirm that our Ministry of Education has now nominated the 20 technicians and made arrangements for them to be released from other duties. The World Health Organization has also confirmed that it is willing to underwrite all tuition and subsistence costs.

However, the selection board in Piflonia did have a particular anxiety; that is, the standard of English in Piflonia is regrettably considerably lower than in the state of Tefloonia, and therefore, concern was expressed regarding the ability of the group to understand their lectures and carry out their other assignments. I wonder therefore if you have any suggestions as to what might be done in the eventuality of a problem arising with English.

I remain,

Yours sincerely,

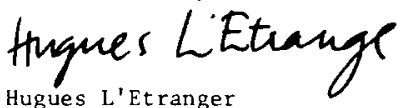

Hugues L'Etranger

EDUCATION ATTACHÉ

The case study has so far been offered in three formats:

A. Long Version (one afternoon a week for eight consecutive weeksAston University). This version contained some features not found in the shorter versions.

(i) A workshop on the details of costing run by the Head of the Department of Modern Languages of Aston University.

(ii) A talk by the Principal of a leading English-language school giving the ESP administration procedures typical of the private sector in England. 
Letter from Teflomine

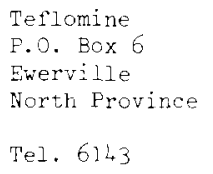

Assistant Dean for Internal and External Services

Hornby Polytechnie

P.O. Box 107

our ref. LES/MOR/123

(last week)

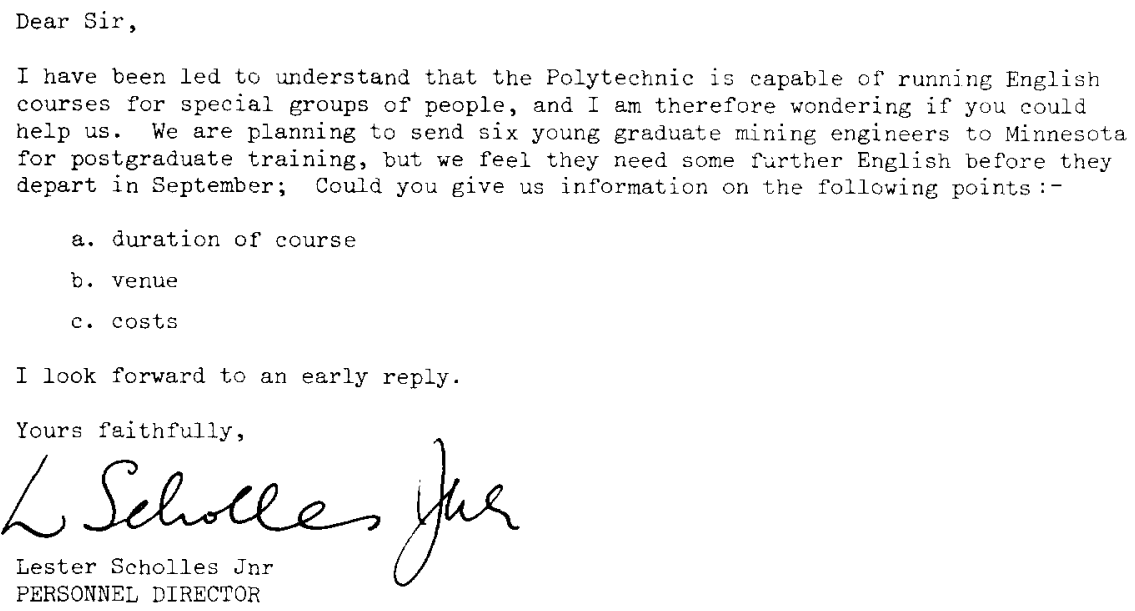

(iii) The involvement of a recently retired member of Aston University known for his skills as a member of an Appointments Board in the selection procedure stage.

(iv) The requirement that the role-playing teams submit an organised dossier of all the correspondence and memoranda generated.

B. Intensive Version (two and one-half days intensive course-Aston University). As in the Long Version, the staff selection phase was reached, and a showing of the Video Arts film Manhunt was also included, but the costing and documentation aspects were much reduced.

C. Short Version (one afternoon workshop given at the EST Conference at the Department of Humanities, University of Michigan, Ann Arbor). This single-slot variation was entirely oral, with the various teams reporting back after two and one-half hours on the various stages they had reached and the various decisions taken in the planning process. 
Letter from Attorney-General's Office

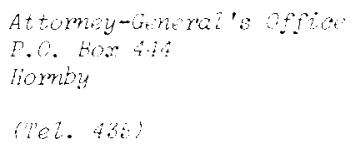

ADIES

Homby Polyteohnic

Dear John,

Further to our conversation at the Minister's roption last wek, I en wi

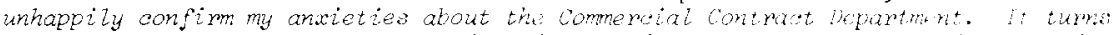

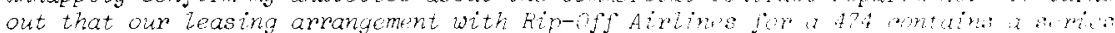

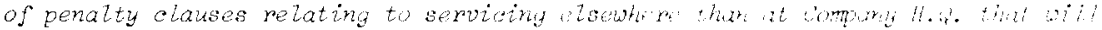

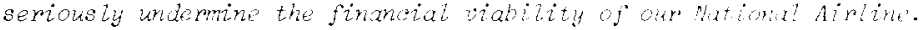

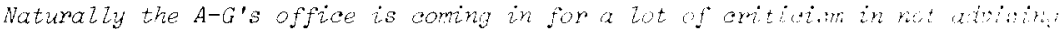
the Ministry of Comminations of the likely imticatione of not earyiny

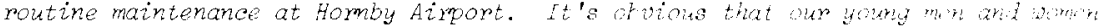
in the commereial Contraet bepartment aren't wo to the job of wping with the fin

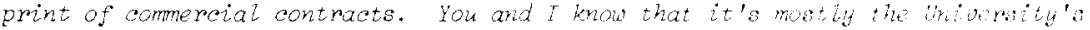
fautt, as it insists on teaching nothing but civil, criminal art national smmpial

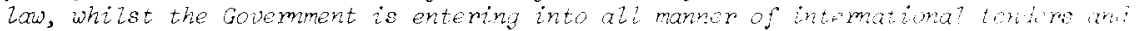

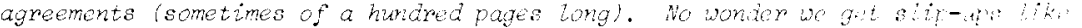
this.

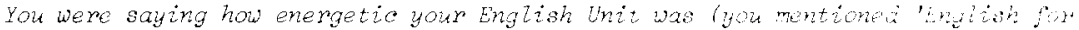
Special Eurposes' or something). Do you think they could do something abot it?

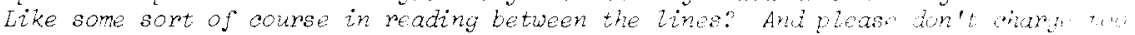
much - there's not mich left in our training budget.

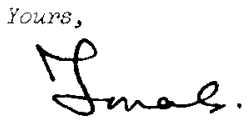

Jonas whate (Deputy Attomin-General)

In all versions, colleagues were drafted in to play various roles, and in the Long and Intensive Versions postgraduate research students were asked to apply for vacancies and attend interviews.

In retrospect, the designer of the material was struck most by two phenomena. First, there was a remarkable disparity between the teams in their attitude to the Polytechnic administration, in the ways in which they set about approaching the three sets of negotiation, in their proposed solutions, and in the variance in costing for basically similar programmes. The Tefloonia case study is apparently repercussive in that an initial decision or initial stance had considerable "knock-on" effects for the rest of its duration, and "repair" on either side proved difficult. Second was the remarkably similar way in which all the teams hung back from ne- 
gotiation and preferred to huddle in their "staff rooms" devising elaborate schemes, only to have them founder on the rocks of administrative impossibility when they tardily discussed them with the various parties involved. Through this experience, the dangers and limitations of a narrow course design focus were hopefully made manifest.

From the student's point of view the administrative demands made by the case study will usually, but not always, be outside his or her experience. It is hardly surprising therefore that all the groups who have taken part to date tended to give more consideration to course design, with which they feel more at home, than to the administrative aspects referred to earlier: establishing good customer relations, gathering relevant information, producing realistic costings, and attending to personnel matters.

It takes time and experience to learn how to be a successful administrator, and a case study (as acknowledged in Management Schools) is essentially little more than an opportunity to interact with certain sets of variables in a simulated setting. As costing is an important and somewhat technical area unfamiliar to most practising ESP teachers, some direct instruction in this administrative skill is probably necessary. A case can possibly be made for other more formal inputs; some of the nonnative speakers of English expressed disappointment at there being no session on administrative correspondence. Both native and nonnative speakers felt that the writing of personal references, if the case study progresses this far, is such a difficult undertaking (partly because the conventions are likely to be known only to those who are experienced in writing and reading them, and partly because they tend to be culturally specific) that a guided discussion of examples would have been a worthwhile addition.

Within the group, the question of leadership can be problematic. In a group of mixed nationality, including British, we tended to make one of the overseas students "Lecturer-in-Charge", while the British member(s) of the team acted as "expatriate specialist(s)". Much depends of course on the people involved: if the "Lecturer-in-Charge" lacks confidence, he or she can be eclipsed by the strongest personality, or else the natural leader hangs back and the "ESP Unit" suffers from lack of leadership. The case study is designed in such a way that each member of the group feels that he or she can contribute "administratively", and this works well in terms of liaison with outside bodies; but when it comes to decision making the "Lecturer-in-Charge" needs to show some skill at organising and running meetings at which decisions can be made. This is another area in which help is often needed, and the tutors should endeavour to turn these meetings into opportunities for learning.

An interesting factor in comparing the groups was the stand taken on what we might call the "unionization position". Some of the groups were happy to take on extra work, no doubt for the best of intentions, such as to enhance the reputation of the Unit, and with it their own career prospects. One of the groups, however, took an entirely different approach. For them the case study was an opportunity to demonstrate their group solidarity in the face of pressure from "the management" (the "Assistant 
Dean") to impose extra work on them. In this realisation of the case, other aspects of administration-particularly constructive liaison with those requiring courses and a realistic costing of the one course they were willing to undertake-suffered considerably. In contrast, the overwilling groups were overcome by an educational idealism that ignored many of the administrative realities, and thus laid themselves open to an increasing degree of exploitation (although we must presume that at some stage a strong counterreaction would emerge).

This difference in orientation serves to illustrate that, however similar the details of the situation, no two groups of people are likely to react to them in the same way. In each running of the case study, we have come to expect that different administrative aspects will become paramount depending on how the individuals perceive the "facts" and how those perceptions are received by the members of their group. In the case study, the "facts" were as near as possible the same in each realisation, with only the dates altered where necessary. But since it is openended, the outcome of the case depends entirely on the reaction and interaction of the group with each other and with the other participants. Much depends, for example, on the first meeting of the "ESP Unit" with the "Assistant Dean". The group's perception of the exercise will be largely coloured by this encounter.

It is very important, therefore, for the participants to be adequately prepared in advance for the kind of exercise they will be engaged in. Although the Background Papers attempt to set the scene and provide enough detail for the participants to be able to enter into an administrative situation, students who are unfamiliar with role play may need to be encouraged to "let go". A certain willingness on the part of the group to "bend" the case study to include as many aspects of administration as possible is also desirable. One group, for example, was on the point of missing out on some valuable experience: by careful timetabling and rearranging of their holiday dates they were able to offer all the new courses by themselves; however, they were persuaded to take on an extra member of staff in order to go through the process of advertising and interviewing.

This raises the crucial question of the amount of control to be exerted by the tutors during the case study. It will already have been observed that there are potentially a large number of people involved. In addition to the tutors, there is the "Assistant Dean," three "correspondents" requiring new courses, and a minimum of three or four "candidates" to be interviewed for the new post. Real-life specialists may also be brought in to talk about management techniques, costing, interviewing and other aspects of administration. In order not to impose too large a burden on colleagues, the tutors tended to take on roles themselves. While intelligent students (and quick-witted tutors) can easily distinguish between all these different "hats", there is sometimes difficulty in distinguishing the tutors from the players of a role, particularly when the designer of the case study and senior tutor of the ESP administration course is also "Assistant Dean"! We have already mentioned that the groups tended to huddle in 
their "staff rooms"; this may also have been partly due to the fact that they could not turn to the course tutor for advice without crossing lines with the "Assistant Dean".

Our initial experiences in this aspect of ESP teacher training thus suggest that there remains a problem in distinguishing the Dr. Jekyll of supportive course tutor from the Mr. Hyde of "awkward" negotiator. It looks as though-partly as a result of the limited histrionic talent available-we need another member of staff (who would not have any role or roles to play) to act as advisor to the teams during the progress of the case and take on the responsibility of evaluating the performance of all the players. As matters now stand, the activities of nine different ESP Units at the Polytechnic in Tefloonia have not been often touched by administrative brilliance, and thus some appreciation of the hard facts that ESP administration is neither unimportant nor easy has been gained, but we need to consider whether we would be wiser to accede to requests for a second chance at the exercise (which might involve sacrifice of other aspects of ESP professional development) or to preface the case illustrated here with some less complex simulation.

\section{REFERENCES}

Abbott, G. 1978. Motivation, Materials, Manpower and Methods: Some Fundamental Problems in ESP. Individualization in Language Learning, 98-104. E. Smyth (Ed.). ELT Documents 103. London: The British Council.

Bachman, L. F. and G. J. Strick. 1981. An Analytic Approach to Language Program Design, in Mackay and Palmer (1981), 45-63.

British Council. n.d. Dunford Papers in ELT Course Design. London: The British Council.

Candlin, C. N. and M. P. Breen. 1979. Evaluating and Designing Language Teaching Materials. Practical Papers in English Language Education, Vol. 2, 172-216. Lancaster: Institute for English Language Education, University of Lancaster.

Candlin, J., D. Charles and J. Willis. 1982. Video in English Language Teaching. Language Studies Unit Research Report. Birmingham: Language Studies Unit, The University of Aston in Birmingham.

Chamberlain, R. G. D. and M. K. S. Flanagan. 1978. Developing a Flexible ESP Programme Design. English for Specific Purposes, 36-55. R. A. Hawkey (Ed.). ELT Documents 101. London: The British Council.

Christy, E. 1978a. General Procedures of ESP Administration. English for Science and Technology 12:2 and 13:3. Corvallis, Oregon: English Language Institute, Oregon State University.

Christy, E. 1978b. The Budget's Role in the Administration of English for Special Purposes Programs. English for Science and Technology 17:38. Corvallis, Oregon: English Language Institute, Oregon State University. 
Cleese, J. and N. Bowler. Manhunt. Video Arts, 68 Oxford Street, London W1N 9LA.

Drobnic, K. 1978. Mistakes and Modification in Course Design: An EST Case History, in Todd Trimble, Trimble, and Drobnic (1978), 313-321.

Hirayama-Grant, G. and M. Sedgwick. 1978. ESP Syllabus Design Processes in Retrospect, in Todd Trimble, Trimble, and Drobnic (1978), 322-336.

Mackay, R. 1981a. Developing a Reading Curriculum for ESP, in Selinker, Tarone, and Hanzeli (1981), 134-145.

Mackay, R. 1981b. Accountability in ESP Programs. The ESP Journal 1,2:107-122.

Mackay, R. and M. Bosquet. 1981. LSP Curriculum Development-From Policy to Practice, in Mackay and Palmer (1981), 1-28.

Mackay, R. and J. D. Palmer (Eds.). 1981. Languages for Specific Purposes: Program Design and Evaluation. Rowley, Massachusetts: Newbury House Publishers, Inc.

Selinker, L., E. Tarone, and V. Hanzeli (Eds.). 1981. English for Academic and Technical Purposes. Rowley, Massachusetts: Newbury House Publishers, Inc.

Sinclair, J. M. 1978. Issues in Current ESP Project Design and Management. ESP-MALS Journal (Summer 1978), 104-125.

Swales, J. M. 1980. The Educational Environment and its Relevance to ESP Programme Design. Projects in Materials Design, 61-70. E. Smyth (Ed.). ELT Documents Special. London: The British Council.

Todd Trimble, M., L. Trimble, and K. Drobnic (Eds.). 1978. English for Specific Purposes: Science and Technology. Corvallis, Oregon: English Language Institute, Oregon State University.

Widdowson, H. G. 1981. English for Specific Purposes: Criteria for Course Design, in Selinker, Tarone, and Hanzeli (1981), 1-11.

John Swales is Reader in English for Specific Purposes and Course Tutor for the MSc in TESP, Language Studies Unit, University of Aston in Birmingham. He has held various teaching and administrative positions in England, Italy, Sweden, Libya and the Sudan. His previous post was Director, English Language Servicing Unit, University of Khartoum, 197378. He is author of Writing Scientific English (1971), co-author of English in the Medical Laboratory (1980), and author of Episodes in EST: A reference work illustrating the development of ESP 1962-1982 (Pergamon, forthcoming in 1983). He has written numerous articles on ESP and related fields and was founder and former editor of ESPMENA Bulletin.

Hugh L'Estrange was a social worker and work study officer among other things before becoming a teacher. After receiving his BEd he taught in a secondary school in England and then moved into EFL in West Germany, where he taught in various firms in and around Munich and at the British Council ESP centre there. He has just completed the MSc in TESP at the University of Aston in Birmingham. 